\title{
Air-Sea Momentum Fluxes during Tropical Cyclone Olwyn
}

\author{
JOEY J. VOERMANS \\ Department of Infrastructure Engineering, University of Melbourne, Victoria, Australia \\ HENRIQUE RAPIZO \\ MetOcean Solutions, Raglan, New Zealand \\ HONGYU MA \\ Department of Infrastructure Engineering, University of Melbourne, Victoria, Australia, and First Institute of Oceanography, \\ Ministry of Natural Resources, Qingdao, China \\ FANGLI QIAO \\ First Institute of Oceanography, Ministry of Natural Resources, Qingdao, China
}

ALEXANDER V. BABANIN

Department of Infrastructure Engineering, University of Melbourne, Victoria, Australia, and Laboratory for Regional Oceanography and Numerical Modeling, Qingdao National Laboratory for Marine Science and Technology, Qingdao, China

(Manuscript received 9 December 2018, in final form 19 March 2019)

\begin{abstract}
Observations of wind stress during extreme winds are required to improve predictability of tropical cyclone track and intensity. A common method to approximate the wind stress is by measuring the turbulent momentum flux directly. However, during high wind speeds, wave heights are typically of the same order of magnitude as instrument heights, and thus, turbulent momentum flux observations alone are insufficient to estimate wind stresses in tropical cyclones, as wave-induced stresses contribute to the wind stress at the height of measurements. In this study, wind stress observations during the near passage of Tropical Cyclone Olwyn are presented through measurements of the mean wind speed and turbulent momentum flux at 8.8 and $14.8 \mathrm{~m}$ above the ocean surface. The high sampling frequency of the water surface displacement (up to $2.5 \mathrm{~Hz}$ ) allowed for estimations of the wave-induced stresses by parameterizing the wave input source function. During high wind speeds, our results show that the discrepancy between the wind stress and the turbulent stress can be attributed to the wave-induced stress. It is observed that for $u_{*}>1 \mathrm{~m} \mathrm{~s}^{-1}$, the wave-induced stress contributes to $63 \%$ and $47 \%$ of the wind stress at 8.8 and $14.8 \mathrm{~m}$ above the ocean surface, respectively. Thus, measurements of wind stresses based on turbulent stresses alone underestimate wind stresses during high wind speed conditions. We show that this discrepancy can be solved for through a simple predictive model of the wave-induced stress using only observations of the turbulent stress and significant wave height.
\end{abstract}

\section{Introduction}

Tropical cyclone intensity, track, storm surge, and associated wave fields are critically determined by the fluxes of momentum between the air and the sea (Emanuel 1995; Black et al. 2007). Our ability to predict the dynamics of these extreme events relies on our

Corresponding author: Joey Voermans, jvoermans@unimelb.edu.au understanding of the physical processes that underlie these exchanges (e.g., Rogers et al. 2006).

The wind transfers momentum to the sea through the wind stress $\tau=\rho u_{*}^{2}$, where $u_{*}$ is the shear velocity and $\rho$ is the air density, and is fundamentally defined as

$$
\tau(z)=\tau_{t}+\tau_{w}+\tau_{v}
$$

where $\tau_{v}$ is the viscous stress, $\tau_{w}$ is the wave-induced stress, and $\tau_{t}$ is the turbulent stress (Tsagareli et al. 2010; 
Chalikov and Rainchik 2011). Viscous forces are driven by the differential velocity between the wind and the ocean and decay rapidly away from the surface. Turbulent stresses are absent at the ocean surface but dominate momentum transport outside the layer that is directly impacted by the presence of the waves (known as the wave-boundary layer). Within the wave-boundary layer, stresses are imposed on the air by the waves by altering the coherent pressure and velocity fluctuations of the air (e.g., Donelan et al. 2006). While these individual stresses vary with distance from the surface, $\tau$ remains relatively constant throughout the near surface layer, thus referred to as the constant-flux layer. The wind stress can therefore be obtained by determining the individual stresses at any height within the constant-flux layer. Unfortunately, there is no straightforward practical approach as yet to determine the individual stresses during high wind speeds and hence the wind stress.

To overcome our inability to predict the individual stresses, the wind stress $\tau$ is often modeled by translating between the shear velocity and wind speed through the use of a drag coefficient $C_{D}$ (e.g., Komen et al. 1994):

$$
\tau=\rho u_{*}^{2}=\rho C_{D} \bar{U}_{10}^{2},
$$

where $\bar{U}$ is the horizontal wind speed at $10 \mathrm{~m}$ above the sea surface. As $C_{D}$ integrates three different processes into a single coefficient, characterizing $C_{D}$ in terms of atmospheric and sea state variables is complex. This is evident from the large scatter observed in $C_{D}$ during high wind speeds both in the field and in numerical models (e.g., Holthuijsen et al. 2012; Liu et al. 2017) and is, in part, attributed to the limited observations of momentum fluxes during extreme winds (Potter et al. 2015). To improve the predictability of $C_{D}$ (and hence the air-sea momentum exchange), more observations of wind stress, and particularly the stress contributions, are required in tropical cyclones.

A common approach to determine the wind stress is by measuring the wind speed profile above the sea surface:

$$
\bar{U}(z)=\frac{u_{*}}{\kappa} \ln \left(\frac{z}{z_{0}}\right)-\psi,
$$

where $\kappa=0.4$ is the Von Kármán constant, $z$ is the vertical distance from the sea surface, $z_{0}$ is the roughness length scale, and $\psi$ is the flux profile relation (Paulson 1970; Donelan 1990). The first part on the right-hand side of Eq. (3) is commonly known as the "law of the wall" and provides the neutral wind speed $\bar{U}_{N}$, whereas the second part arises from buoyancy-driven turbulence (Monin and Obukhov 1954). Although this measurement approach seems rather straightforward, the method requires at least two measurements of wind speed to estimate $u_{*}$ from the theoretical wind profile. This is further complicated by the dynamics of the instruments, which can be mounted on wave-following structures where the acquired data then requires corrections to account for their oscillating motions (Anctil et al. 1994; Edson et al. 1998). Tower-based wind meters or fixed masts are a good alternative to prevent significant contamination, but installation is typically restricted to shallow areas. Moreover, to account for buoyancy-induced turbulence, fluxes of humidity and heat are required to determine $u_{*}$ from the wind speed profile (Drennan et al. 2003).

Alternatively, the eddy-correlation method is the most direct approach in measuring the momentum flux (e.g., Large and Pond 1981). The turbulent stress is given by the covariance of the horizontal and vertical velocity component (also known as the Reynolds stress):

$$
\tau_{t}=-\rho \overline{U^{\prime} w^{\prime}} .
$$

Here, Reynolds averaging is applied to obtain the fluctuating velocity components, that is, $U=\bar{U}+U^{\prime}$, where $\bar{U}$ is the ensemble averaged velocity and $U^{\prime}$ is the turbulent velocity component. Note that $U$ is the horizontal velocity vector of the velocity components $u$ and $v$ in the horizontal plane. When the turbulent flux is measured sufficiently away from the ocean surface (but still close enough to be within the constant-flux layer), turbulent momentum transport dominates the total momentum transport $\left(\tau \approx \tau_{t}\right)$. The eddy-correlation method has the advantage that only one measurement point is required to determine the flux. The sampling frequency should, however, be high enough to measure all turbulent scales that contribute to the wind stress.

The assumption that the measured turbulent flux dominates the wind stress fails when high wind speeds are encountered as wave heights start to become of the same order of magnitude as the instrument height [typically stationed at $O(10) \mathrm{m}$ away from the ocean surface]. As the wave-boundary layer thickness is approximately $3.7 H_{s}$ (Chalikov 1995), turbulence instruments are thus usually deployed well within the wave-boundary layer during tropical cyclones where wave-induced stresses cannot be ignored (Babanin et al. 2018). The eddy-correlation method alone is then insufficient to characterize $u_{*}$ during extreme wind events. Hence, structural details of the stress contributions within the wave-boundary layer are required to improve the understanding and predictability of wind stresses during tropical cyclones.

This study presents observations and estimates of wind stress and stress contributions during extreme wind conditions. Wind measurements and stress estimates are corrected for instrument motions and buoyancy effects. 


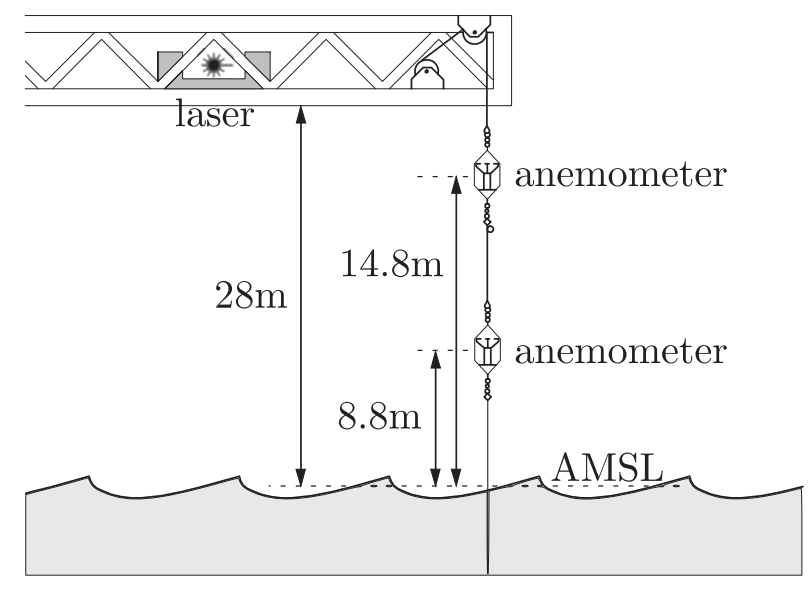

FIG. 1. Schematic of the flare bridge and the instrument setup. Anemometers are positioned 8.8 and $14.8 \mathrm{~m}$ MSL, respectively. The laser is positioned $28 \mathrm{~m}$ MSL.

Through the modeling of the wave-induced stress we show that wind stress estimates from turbulent flux measurements alone underestimate the wind stress during high wind speeds. We do so by using data from a fixed offshore platform, located near the storm track of Tropical Cyclone Olwyn in March 2015.

\section{Methods}

\section{a. Experiment overview}

Measurements were taken from a fixed offshore platform located on the north shelf of Western Australia $\left(116^{\circ} 8.202^{\prime} \mathrm{E}, 19^{\circ} 35.136^{\prime} \mathrm{S}\right), 135 \mathrm{~km}$ from the nearest coastal line and at a local water depth of $124 \mathrm{~m}$ (lowest astronomical tide; Fig. 1). The site is within the latitude range of strong cyclonic activity and is an area prone to one of the highest occurrences of tropical cyclones in the world (Peduzzi et al. 2012). For observational and modeling purposes, the platform contains various instruments to measure atmospheric and oceanographic conditions. In 2014, a data acquisition program was implemented to measure and study surface fluxes during tropical cyclones, data of which is used in this study.

In 2015, the instruments recorded momentum fluxes during the near passage of Severe Tropical Cyclone Olwyn. The cyclone center passed at approximately 150 and $300 \mathrm{~km}$ from the fixed offshore platform with minimum central pressures of 955 and $950 \mathrm{hPa}$, respectively (Fig. 2). The events occurred within a one month time frame, in March and April 2015. Very few other cyclones with reasonable proximity to the platform were recorded since then, especially due to the very quiet $2015 / 16$ cyclone season.

Water surface displacements were recorded by four lasers gauges (Optech Sentinel 3100) in a rectangular

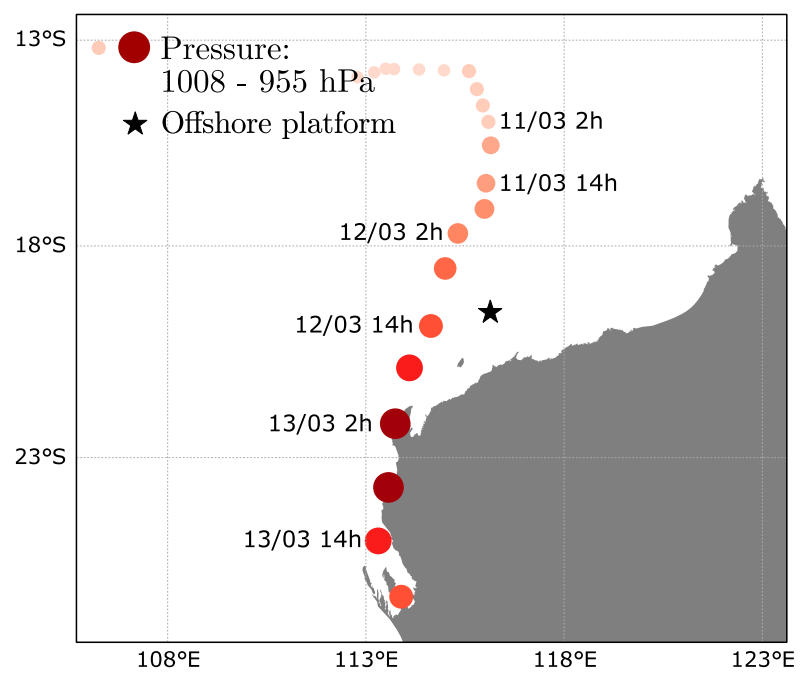

FIG. 2. Location of the fixed offshore platform and track of Tropical Cyclone Olwyn during March-April 2015. Color and size of markers define the cyclone intensity. Data were obtained from the Australian Bureau of Meteorology, and time is in Western Standard Time (WST).

array of $1.3 \mathrm{~m} \times 1.7 \mathrm{~m}$ positioned on the flare bridge at approximately $28 \mathrm{~m}$ above mean sea level (MSL; see Fig. 1). The distance to the water surface is concurrently sampled at a frequency of $5 \mathrm{~Hz}$, allowing for the measurement of high-frequency wave up to $2.5 \mathrm{~Hz}$. Laser attenuation due to sea spray for winds above $20 \mathrm{~m} \mathrm{~s}^{-1}$ were calibrated in laboratory experiments (Toffoli et al. 2011).

Wind speeds were measured by two ultrasonic MasterPro anemometers fixed along a $12-\mathrm{mm}$ moored wire with one end terminating under the platform's flare bridge. The wire was kept under tension by an anchor weight positioned near the sea floor. The threedimensional air velocity components are continuously measured at a sampling frequency of $20 \mathrm{~Hz}$. With this configuration the two anemometers are placed over a vertical line within a $28-\mathrm{m}$ air gap, at chosen heights of about 14.8 and $8.8 \mathrm{~m}$ MSL (Fig. 1). The aim of this configuration is to avoid flow distortion effects and large angles typically produced by ship motions. The two high-frequency air velocity measurements at different vertical levels also allow direct measurements of the vertical profiles of wind and wind stress in the atmospheric boundary layer. Wind sensors installed on the top of the flare and on the main platform are not used as these sensors are more susceptible to flow distortion by the structure. Several other atmospheric properties are measured at $29 \mathrm{~m}$ MSL on the flare bridge, including air temperature, relative humidity, and barometric pressure. To calculate the air-sea temperature difference, water temperature is obtained from a CM-04 current 
meter attached at approximately $10-\mathrm{m}$ water depth to the same moored cable where the anemometers are installed.

\section{b. Postprocessing}

Wind speeds observations were corrected for tilt angle and translational wire motions (e.g., Anctil et al. 1994; Edson et al. 1998). These movements were measured by the Motion Reference Units (MRU) housed in the upper anemometer, such that the true velocity is given by

$$
\mathbf{u}=\mathbf{R}\left(\mathbf{u}_{M}+\mathbf{A}\right),
$$

where $\mathbf{u}$ is the corrected air velocity vector; $\mathbf{R}$ is the rotation matrix; which depends on the yaw, pitch, and roll angles of the MRU; and $\mathbf{A}$ is the translational horizontal velocity vector of the MRU. The subscript $M$ refers to the measured velocity component. It is observed that the anemometer pitch and roll angles produce large corrections on the vertical velocity $w$ (average of $100 \%$ ), but little on the horizontal velocity component $U(0.5 \%)$. Without correction of wire motion, the measured turbulent stress $\tau_{t}$ would be overestimated by up to $16 \%$ for the largest wind speeds observed in this study (Fig. 3). The impact of the wire translation velocity on the velocity measurements is observed to be negligible (up to $0.05 \%$ ). The two velocity components were then corrected by forcing the mean vertical velocity $\bar{w}=0$ using

$$
\begin{aligned}
& U=w_{M} \sin (\theta)+U_{M} \cos (\theta), \\
& w=w_{M} \cos (\theta)-U_{M} \sin (\theta),
\end{aligned}
$$

where $\theta=\arctan (\bar{w} / \bar{U})$.

A 10-min moving average for $U$ is applied to identify nonstationary effects. Atmospheric conditions were regarded to be stationary if the moving average velocity gradient was within $\pm 3 \times 10^{-3} \mathrm{~m} \mathrm{~s}^{-2}$ and records were at least $15 \mathrm{~min}$ long. The time series were then de-spiked by excluding data which deviated at least four times the standard deviation from their respective mean values. Reynolds averaging is applied over periods of $10 \mathrm{~min}$ and records where the mean horizontal velocity $\bar{U}$ was smaller than $5 \mathrm{~m} \mathrm{~s}^{-1}$ are not considered in this study.

\section{c. Estimation of wind stress}

The total wind stress $\tau=\rho u_{*}^{2}$ is defined by Eq. (3) and, following measurements of $\bar{U}$ at the two different anemometer heights, can then be determined through

$$
u_{*}=\kappa \frac{\bar{U}\left(z_{1}\right)-\bar{U}\left(z_{2}\right)}{\ln \left(z_{1} / z_{2}\right)-\psi\left(z_{1} / L\right)+\psi\left(z_{2} / L\right)},
$$

where $L$ is the Obukhov length scale, which can be interpreted as the height above the ocean surface where the production of turbulence by buoyancy is similar in

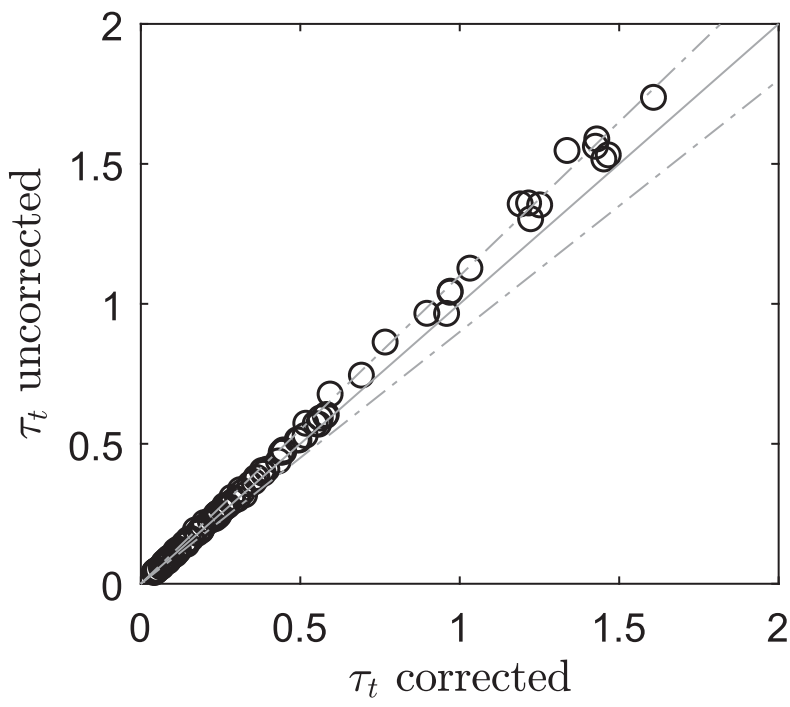

FIG. 3. Impact of wire motion correction on the observed turbulent stress $\tau_{t}$ measured by the anemometer position at $z=$ $14.8 \mathrm{~m}$. Dash-dotted line represent a $10 \%$ deviation from the 1:1 line.

magnitude to that produced by velocity shear. Length scale $L$ is estimated by (e.g., Drennan et al. 2003)

$$
L=\frac{-u_{*}^{3}}{\left\{\kappa g\left[H /\left(c_{p} T_{o}\right)+0.61 E / L_{e}\right] / \rho\right\}},
$$

where $c_{p}$ is specific heat at constant pressure; $T_{0}=$ $T_{a}+\gamma z$ is the reference potential temperature, with air temperature $T_{a}$ and the adiabatic lapse rate $\gamma$; and $L_{e}$ is the latent heat of vaporization. The bulk formulations of the surface heat flux $H$ and rate of evaporation $E$ are defined by (Smith 1988)

$$
\begin{gathered}
H=\rho c_{p} C_{T} \bar{U}_{10 N} \Delta_{T}, \\
E=\rho L_{e} C_{E} \bar{U}_{10 N} \Delta_{q},
\end{gathered}
$$

where $\bar{U}_{10 N}$ is the neutral mean wind speed at $10 \mathrm{~m}$ [i.e., see Eq. (3) and its description]; $\Delta_{T}=T_{s}-T_{0}$ is the potential temperature difference between the sea surface $T_{s}$ and reference height $T_{0}$; and $\Delta_{q}=q_{s}-q(z)$ is the specific humidity difference, where $q_{s}$ is saturation specific humidity and $q(z)$ is the measured specific humidity. Parameters $C_{T}$ and $C_{E}$ are the Dalton and Stanton numbers, respectively, and a value of 0.0012 is used for both (Jeong et al. 2012; Komori et al. 2018). Temperature and humidity parameters were obtained from a meteorological station positioned at the flare bridge at $21.2 \mathrm{~m}$ above the lower anemometer. To calculate $L$, the wind speed from the upper anemometer was neutrally converted to the height of the meteorological station. The sea surface temperature was approximated by the 
CM-04 current meter reading located $10 \mathrm{~m}$ below the surface.
Using the Obukhov length, the flux profile relation can be determined following (Donelan 1990)

$$
\psi(z / L)= \begin{cases}2 \ln \left(\frac{1+\phi}{2}\right)+\ln \left(\frac{1+\phi^{2}}{2}\right)-2 \tan ^{-1} \theta+\pi / 2, & \text { if } z / L<0 \\ -5.4 z / L, & \text { if } z / L>0\end{cases}
$$

where $\phi=(1-17 z / L)^{1 / 4}$. Finally, to obtain $u_{*}$, Eqs. (7)(10) can be solved iteratively, which is found to converge for all records.

\section{d. Estimation of viscous stress}

The viscous stress is determined following a simple drag model:

$$
\tau_{v}=\rho C_{v} \bar{U}_{10}^{2},
$$

where $\bar{U}_{10}$ is estimated through interpolation of the postprocessed mean wind speed at the two anemometer heights within the constant-flux layer. The viscous drag coefficient $C_{v}$ can be estimated by (Tsagareli et al. 2010):

$$
C_{v}=-5 \times 10^{-5} \bar{U}_{10}+1.1 \times 10^{-3} .
$$

For wind speeds above $22 \mathrm{~m} \mathrm{~s}^{-1}, C_{v}$ is kept at zero.

\section{e. Estimation of wave-induced stress}

Two methods are used to estimate the wave-induced stress. The first approach determines $\tau_{w}$ at the ocean surface $(z=0)$ by subtracting the viscous from the total shear stress [determined through Eqs. (7)-(10)]:

$$
\tau_{w}(0)=\rho u_{*}^{2}-\tau_{v}(0)
$$

Though this is an implicit method, as it uses a priori knowledge of the total shear stress through measurements of the shear velocity [Eq. (3)], it provides additional insight in the accuracy of the momentum flux observations.

The second approach uses the wind input source function to determine the wave-induced stress:

$$
\tau_{w}=\int_{\omega} \frac{F_{\text {in }}}{c(\omega)} d \omega
$$

where $F_{\text {in }}$ is the wind input source function, $c(\omega)$ is the phase speed of the wave propagation, and $\omega$ is the radian frequency. The wind input source function is given by

$$
F_{\text {in }}(\omega)=\rho \omega g \gamma(\omega) S(\omega) .
$$

Here, $g$ is the gravitational acceleration, $\gamma(\omega)$ is the temporal growth rate of wave energy, and $S(\omega)$ is the energy density spectrum. For $\gamma$, we use the parameterization by Donelan et al. (2006), as it is shown to be suitable for a wide range of wind and wave conditions

$$
\gamma=G \sqrt{B_{n}}\left(\frac{\bar{U}_{10}}{c}-1\right)^{2}
$$

where $B_{n}(\omega)=\left[\omega^{5} E(\omega) / 2 g^{2}\right] A(\omega)$ is the spectral saturation, $A(\omega)=1.12\left(\bar{U}_{10} / c_{p}\right)^{-0.5}\left(\omega / \omega_{p}\right)^{-0.95}+1 / 2 \pi$ is the directional spreading function (Babanin and Soloviev 1998), and $G$ is the sheltering coefficient defined by

$$
G=2.8-1.0\left\{1+\tanh \left[10 \sqrt{B_{n}}\left(\frac{\bar{U}_{10}}{c}-1\right)^{2}-11\right]\right\} \text {. }
$$

The wave-induced stress, as determined by either Eq. (13) or (14), decreases with distance from the sea surface. The distance at which $\tau_{w}$ has a negligible contribution to the wind stress $\tau$ is of the order of the dominant wavelength of the wave field. As potential flow theory predicts and exponential decay for the waveinduced pressure (e.g., Donelan et al. 2006), the waveinduced stress reduction $\alpha$ within the wave boundary layer is characterized by an exponential function as well:

$$
\alpha(z)=\exp \left(-\beta k_{p} z\right)
$$

where $\beta=1$ is a coefficient (Donelan et al. 2006) and $k_{p}$ is the peak wave number.

\section{f. Estimation of turbulent stress}

Turbulent stresses are obtained through the covariance of the horizontal and vertical components of the turbulent wind velocity [Eq. (4)]. As no MRU is present in the lower anemometer, the Reynolds stress measured at $z=8.8 \mathrm{~m}$ is corrected linearly according to the motion correction found for the anemometer at $z=14.8 \mathrm{~m}$. This assumes that the wire between the anemometers is a line, which is a reasonable assumption as the wire is moored and therefore tensioned.

To assure that turbulent flux measurements are not restricted by the sampling frequency of the anemometers, 
the normalized ogives of the turbulent stresses (the cumulative summation of the turbulent shear stress spectrum $\left.S_{U^{\prime} w^{\prime}}\right)$ should saturate before the sampling frequency. Examples of normalized ogives suggest that saturation is reached well before the sampling frequency (Fig. 4) and, as such, a higher sampling rate will have negligible impact on the mean turbulent flux. Low-velocity cases tend to reach saturation earlier due to a smaller separation of turbulent length scales. The low-velocity case compares well to the saturated ogive of Miyake et al. (1970) which has a comparable mean wind speed of about $5.6 \mathrm{~m} \mathrm{~s}^{-1}$. Hence, these ogives can be used as reference curves to account for turbulent stress contributions not captured by lowerresolution anemometers.

\section{Measured wind and waves during Cyclone Olwyn}

During the near passage of the tropical cyclone the 10min averaged wind speeds at $z=10 \mathrm{~m}$ (interpolated between the two anemometers) were in the range $5-22 \mathrm{~m} \mathrm{~s}^{-1}$ (Fig. 5a), with maximum gust (20-s average) of $27.4 \mathrm{~m} \mathrm{~s}^{-1}$ at the upper anemometer. The wind direction was consistently from east-northeast $\left(90^{\circ}-45^{\circ}\right)$ before and during the recording of the strongest winds. After the passage of the cyclone the wind direction shifted to westerly $\left(270^{\circ}\right)$. Observations of $C_{D}$ for large wind speed, $C_{D} \approx 5 \times 10^{-3}-9 \times 10^{-3}$ (Fig. 5b), are considerably larger than those recorded by others for similar wind speeds, that is, $C_{D} \approx 2 \times 10^{-3}$ (e.g., Holthuijsen et al. 2012; Powell et al. 2003; Edson et al. 2013). In section 5 , the three outliers at $C_{D} \approx 9 \times 10^{-3}$ and the generally large values of $C_{D}$ are further discussed.

The waves during the event reached significant wave height $\left(H_{s}\right.$; i.e., $4 \sqrt{m_{0}}$ where $m_{0}$ is the total variance of the power spectral density of sea surface elevation $S$ ) of $6.6 \mathrm{~m}$ (Fig. 5c). The period of the spectral peak $T_{p}$ was of $10 \mathrm{~s}$ during the highest winds recorded. The development of the wave parameters lead to the conclusion that the waves during the passage of the cyclone were predominantly forced by the local winds. Long period swells were practically nonexistent.

\section{Results}

Comparison of the shear velocity determined from the mean velocity profile $u_{*}$ against the measured Reynolds stresses at the two anemometer heights is shown in Fig. 6. For $u_{*}<0.3$, the turbulent momentum flux reasonably equals the wind stress (i.e., $\tau \approx \tau_{t}$ ), whereas for increasing shear velocity, the contribution of the turbulent stress to the total stress decreases. The increasing

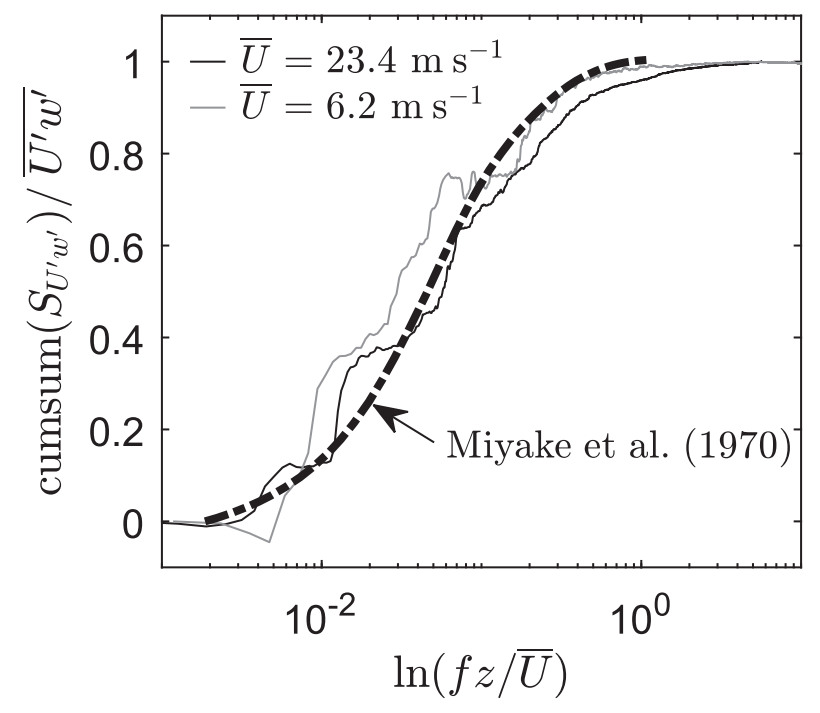

FIG. 4. Ogives of the turbulent momentum flux at the upper anemometer $(z=14.8 \mathrm{~m})$ for a high (black) and low wind speed (gray) record, suggesting that saturation is reached before the sampling frequency. The black dashed curve is an example ogive of a saturated time series from Miyake et al. (1970).

difference between the measured turbulence fluxes between the two anemometers for larger $u_{*}$ suggests that the anemometers become increasingly embedded within the wave boundary layer. For the same reason, the turbulent stress measured at $z=8.8 \mathrm{~m}$ is smaller than the turbulent stress measured at $z=14.8 \mathrm{~m}$.

To identify the wave-induced stress $\tau_{w}$ as the source of the discrepancy between the turbulent flux and wind stress measurements, the wave-induced stress is first estimated at the ocean surface according to Eq. (13). As the viscous stress is negligible outside a very thin layer near the surface, the wind stress can then be compared against the summation of the reduced wave-induced stress (i.e., $\alpha \tau_{w}$ ) and turbulent stress at the two anemometer heights (Fig. 7). The inclusion of the waveinduced stress in the momentum flux estimates at the anemometer heights shows excellent agreement with the wind stress measured from the mean velocity profile.

Independently, the wave-induced stress can be modeled through the wave growth rate parameterization of Donelan et al. (2006) [Eqs. (14)-(17)]. The estimated wind stress at the sea surface [i.e., $\tau(0)=\tau_{v}+\tau_{w}$ ], shows good agreement, with the exception of the three largest wind stress measurements (Fig. 8a). Similarly, the total momentum flux at the two anemometer heights can be estimated by the sum of the reduced wave-induced stress and the turbulent stress (Fig. 8b). Also here, good agreement is observed between the independent estimates of the total stress in the constant-flux layer. 

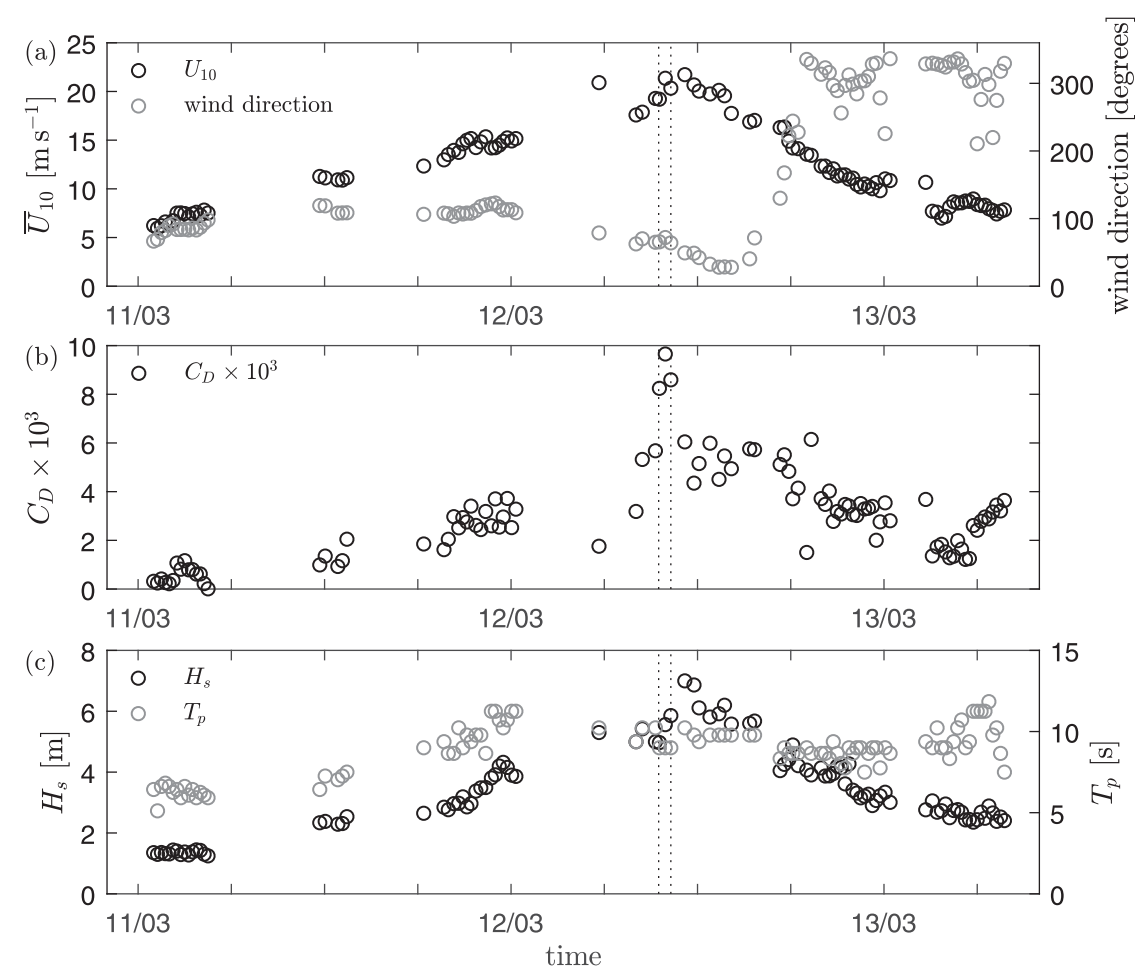

FIG. 5. Time series of (a) the mean wind speed at $10 \mathrm{~m}$ above the sea surface in black (interpolated between the two anemometers) and wind direction in gray; (b) drag coefficient [as per Eq. (2)]; (c) significant wave height (black) and peak period (gray), between 11 and 13 Mar 2015. Dashed lines indicate the three outliers observed in Figs. 7-8.

\section{Discussion}

Observations of wind stresses during the near passage of Tropical Cyclone Olwyn show that the observed difference between the wind stress and the turbulent momentum flux in the wave boundary layer is balanced by the wave-induced stress and viscous stress (Figs. 7, 8). There are, however, three instants observed where these stresses do not balance. While these outliers coincide with the highest measured wind stresses in the dataset, they do not correspond to the largest observed wind speeds (see dashed lines in Fig. 5). They occurred during large accelerations of the wind speed, about $3 \mathrm{~m} \mathrm{~s}^{-1}$ in $45 \mathrm{~min}$. When the contribution of the wave-induced stress [estimated using Eqs. (14)-(17)] to the total stress in the constant-flux layer is evaluated (Fig. 9), it suggests that the three outliers (note, the three outliers are those with the highest $u_{*}$ ) deviate from the observed overall trend, particularly for the lower anemometer. As the observed wind acceleration does not seem to cause any predictive uncertainties of the wave-induced stress parameterization used (Donelan and Plant 2009), this deviation from the trend could be interpreted as an overprediction of $u_{*}$ instead. For instance, using estimates of $u_{*}$ for the three outliers based on the summation of $\tau_{t}$ and $\tau_{w}$ (e.g., as in Fig. 8b) to determine a representative drag coefficient, values of $C_{D}$ in the range of $3.4 \times 10^{-3}-5.2 \times 10^{-3}$ are obtained, which are consistent with the other values of $C_{D}$ observed in this study

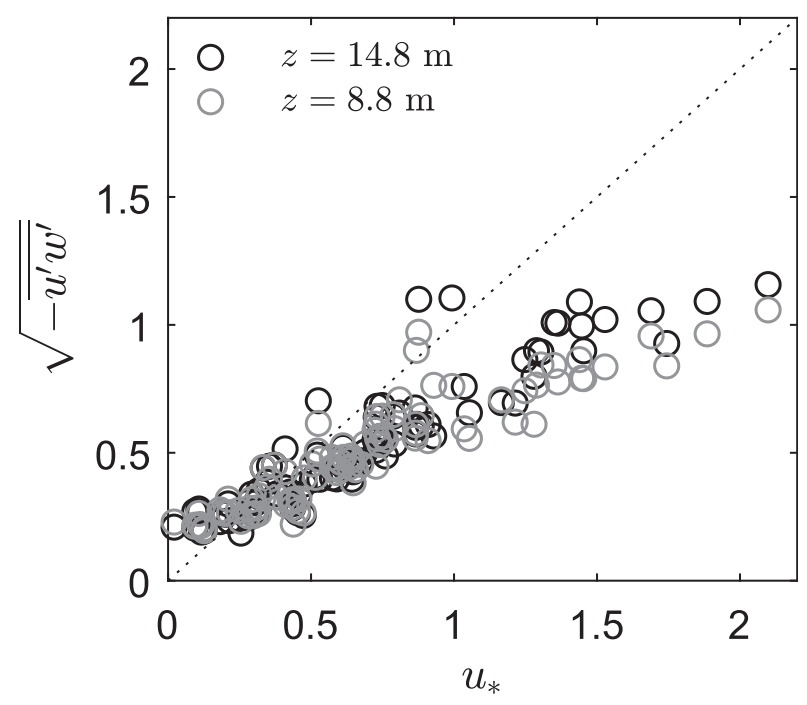

FIG. 6. The measured shear velocity $u_{*}$ [Eq. (3)] against the turbulent momentum flux $\left(-\overline{u^{\prime} w^{\prime}}\right)^{1 / 2}$ at heights $z=8.8 \mathrm{~m}$ (gray) and $z=14.8 \mathrm{~m}$ (black). 


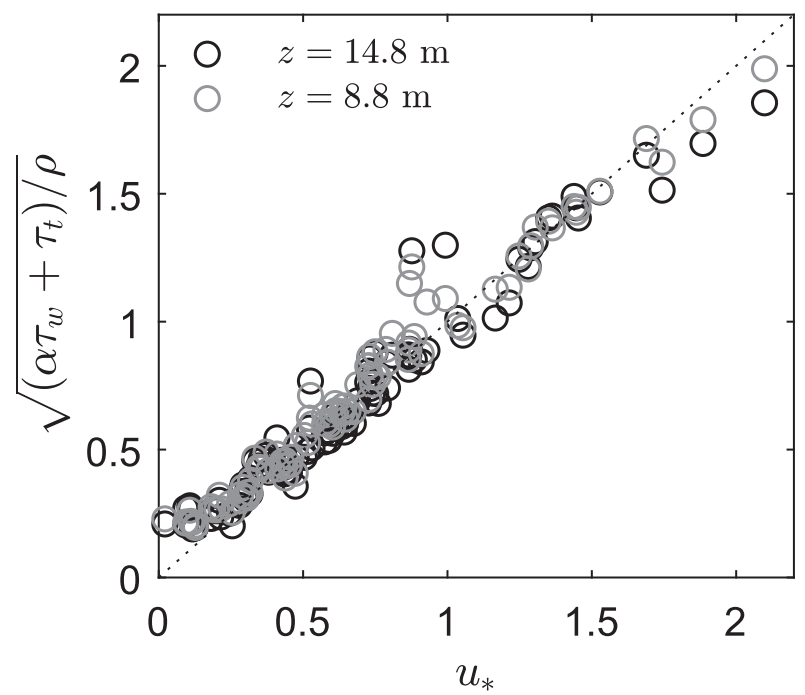

FIG. 7. The measured shear velocity $u_{*}$ [Eq. (3)] against the estimated shear stress in the constant-flux layer at heights $z=8.8 \mathrm{~m}$ (gray) and $14.8 \mathrm{~m}$ (black). Here, $\tau_{w}$ is estimated by subtracting the viscous and turbulent stress from the measured total stress [Eq. (13)].

(Fig. 5b). Physically, the overprediction of $u_{*}$ by the mean wind speed profiles could be explained by the slow development of the sea state during accelerating winds and hence a slower response of the shear velocity to such wind speed changes (Donelan and Plant 2009). A slow response of the wave field is, in part, substantiated by a noticeable smaller $H_{s}$ compared to similar wind speeds in the time series (Fig. 5c). Alternatively, it is also possible that the outliers (with large $u_{*}$ ) signify a dynamic transition in momentum transport across the air-sea interface where the aerodynamic roughness reaches

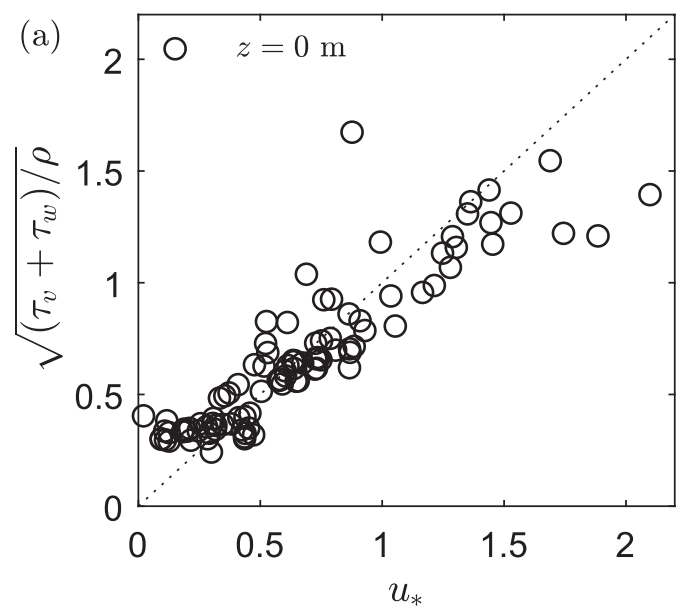

saturation (e.g., Donelan et al. 2004; Takagaki et al. 2012).

As $u_{*}$ corresponds well to the independent estimate of $\sqrt{\left(\alpha \tau_{w}+\tau_{t}\right) / \rho}$, the high values of $C_{D}$ as in Fig. 5b are considered to be accurate. Large values of $C_{D}$ observed in this study could be the result of the directional misalignment of long waves with the wind during the passage of the cyclone along the measurement site (Young 2006), where the misalignment between the long waves and the wind direction can increase the wind stress (Holthuijsen et al. 2012; García-Nava et al. 2009). This could also explain the different $C_{D}$ observed for similar wind speed $\left(\approx 15 \mathrm{~m} \mathrm{~s}^{-1}\right)$ but different wind direction just before and after the passage of the tropical cyclone (i.e., $C_{D} \approx 3 \times 10^{-3}$ and $5 \times 10^{-3}$, respectively, for $\bar{U}_{10} \approx$ $15 \mathrm{~m} \mathrm{~s}^{-1}$ ). However, further study is required to determine the exact impact of long waves and directional spreading on $C_{D}$, particularly its dependency on wind speed.

Due to the increase of the wave-boundary layer thickness $h_{\mathrm{WBL}}$ with significant wave height, that is, $h_{\mathrm{WBL}} \approx$ 3.7H (Chalikov 1995), turbulence flux measurements during extreme wind conditions are generally insufficient to measure wind stresses as these instruments are typically positioned $O(10) \mathrm{m}$ above the ocean surface. For instance, it is observed here that for $u_{*}>1 \mathrm{~m} \mathrm{~s}^{-1}$, the wave-induced stress contributes to approximately $47 \%$ of the wind stress at $z=14.8 \mathrm{~m}$ [i.e., $\left.\alpha \tau_{w} /\left(\alpha \tau_{w}+\tau_{t}\right)\right]$ and $63 \%$ at the lower anemometer at $z=8.8 \mathrm{~m}$ (Fig. 9). Hence, measurements of wind stresses based on $\tau_{t}$ alone during extreme wind conditions need to be compensated for the wave-induced stress.

As $\tau_{t}$ and $\tau_{w}$ are strongly coupled in the constant flux layer (i.e., when viscous contributions are negligible, the sum of $\tau_{t}$ and $\tau_{w}$ is constant), turbulent stress

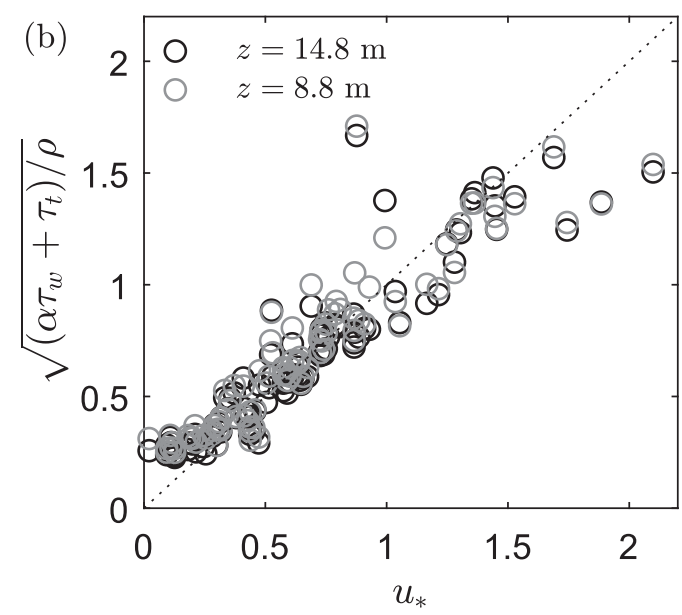

FIG. 8. The measured shear velocity $u_{*}$ [Eq. (3)] against the estimated shear stress in the constant-flux layer at heights (a) $z=0 \mathrm{~m}$ and (b) $z=8.8 \mathrm{~m}$ (gray) and $14.8 \mathrm{~m}$ (black). Here, $\tau_{w}$ is estimated by the wind input source function parameterization of Donelan et al. (2006) [Eqs. (14)-(17)]. 


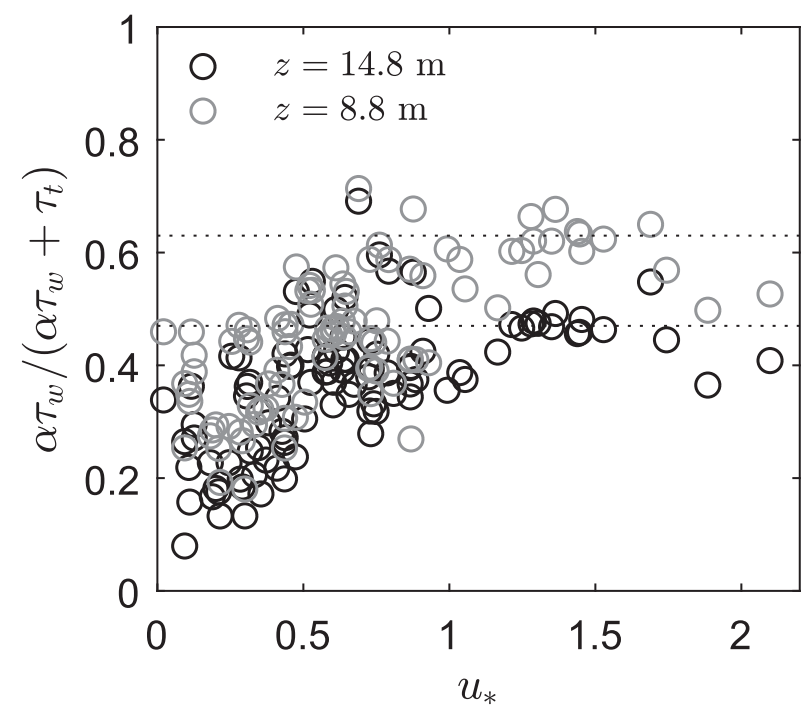

FIG. 9. The contribution of the wave-induced stress $\left(\alpha \tau_{w}\right)$ to the total shear stress $\left[\alpha \tau_{w} /\left(\alpha \tau_{w}+\tau_{t}\right)\right]$ at $z=8.8 \mathrm{~m}$ (gray) and $14.8 \mathrm{~m}$ (black). Dashed lines correspond to 0.47 and 0.63 . Here, $\tau_{w}$ is estimated by the wind input source function parameterization of Donelan et al. (2006) [Eqs. (14)-(17)].

observations can be corrected and used to obtain estimates of the wind stress within the wave boundary layer. Given that the magnitude of the wave-induced stress depends on the relative distance to the surface (i.e., $\left.z / H_{s}\right)$, the turbulent stress correction is then formulated as $\tau_{w} \approx \exp \left(-m z / H_{s}\right) \tau$, where $m$ is a constant of proportionality and likely varies with sea state variables. This assumes that the contribution of the viscous stress is negligible, such that $\tau_{w} \approx \tau$ for $z / H_{s} \ll 1$ and $\tau_{w} \approx 0$ for $z / H_{s} \gg 1$. Using Eq. (1), the wave-induced stress at the instrument height can then be expressed in terms of the measured turbulent stress:

$$
\tau_{w}=\frac{\exp \left(-m z / H_{s}\right)}{1-\exp \left(-m z / H_{s}\right)} \tau_{t} .
$$

Here, a best-fit value of $m=0.3$ is used. Comparison of $\tau_{w}$ based on the parameterization of Donelan et al. (2006) [i.e., Eqs. (14)-(17)] and Eq. (19) suggest that this simple correction of the turbulent stress can be used to compensate for the missing wave-induced stress (Fig. 10a). Estimating $\tau_{w}$ based on observations of $\tau_{t}$ alone seems to fail when wind speed and significant wave height become small. In particular, for wind speeds below $\sim 8 \mathrm{~m} \mathrm{~s}^{-1}$ (Fig. 10a), the viscous contributions cannot be ignored anymore (Kudryavtsev and Makin 2001). Through a best-fit (Fig. 10b), the underestimation of the wave-induced stress by Eq. (19) for low wind speeds can be corrected for and yields

$$
\tau_{w}=\left[\frac{\exp \left(-m z / H_{s}\right)}{1-\exp \left(-m z / H_{s}\right)}+0.2\right] \tau_{t} .
$$

The results of this study suggest that wind stresses in extreme conditions (at least up to $\bar{U}_{10}=22 \mathrm{~m} \mathrm{~s}^{-1}$ ) are well estimated based on the stress partitioning of Eq. (1). This implies that the wind stresses generated by high wind speeds can be predicted with knowledge of the
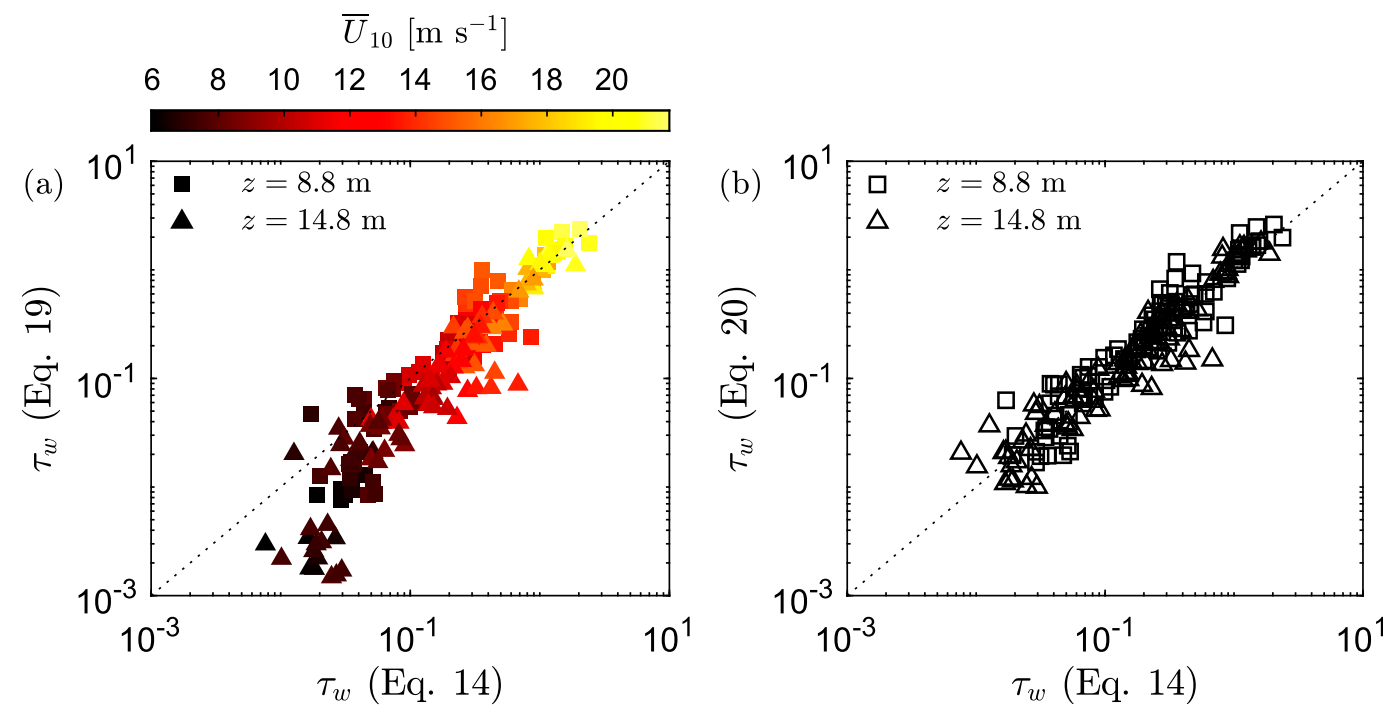

FIG. 10. Comparison of wave-induced stress estimates based on the parameterization of Donelan et al. (2006) [Eqs. (14)-(17)] and based on the observations of the turbulent stress using (a) Eq. (19) and (b) Eq. (20). In (a), $\tau_{w}$ is compared against the wind speed. Squares and triangles represent measurements at anemometer heights $z=8.8 \mathrm{~m}$ and $z=14.8 \mathrm{~m}$, respectively. 
wave field and average wind speed only based on the parameterization of Donelan et al. (2006) [i.e., $\tau(0)=$ $\tau_{v}+\tau_{w}$ ], or by correcting measurements of the turbulent momentum flux by wave-induced stresses following Eq. (20).

\section{Conclusions}

Wind stress observations during the near passage of Tropical Cyclone Olwyn are presented using measurements of wind speed profiles and turbulent momentum fluxes. During low wind speeds and small wave heights, turbulent flux measurements are sufficient in describing wind stress as typical instruments heights, $O(10) \mathrm{m}$, are outside the wave-boundary layer. However, during extreme winds, significant wave heights are often large such that turbulence instruments are deeply embedded within the wave-boundary layer. Our results confirm that at such events, the discrepancy between the wind stress and the turbulent stress is balanced by the waveinduced stress. The wave-induced stress for $u_{*}>1 \mathrm{~m} \mathrm{~s}^{-1}$ contributes to $63 \%$ and $47 \%$ of the wind stress at 8.8 and $14.8 \mathrm{~m}$ above the ocean surface, respectively. While this implies that stress measurements during extreme wind conditions cannot be captured by turbulent momentum flux observations alone, we show in this study that the required wave-induced stress is well predicted by $\tau_{w}=\tau_{t} \exp \left(-0.3 z / H_{s}\right)\left[1-\exp \left(-0.3 z / H_{s}\right)\right]^{-1}+0.2 \tau_{t}$, using only observations of the turbulent stress and significant wave height.

Acknowledgments. This research was supported by the DISI Australia-China Centre through Grant ACSRF48199. AVB acknowledges ARC Discovery Grant DP170101328. Data were kindly provided by Woodside Ltd, and the authors can be approached regarding the data used in this study. We thank the work and technical support from John Masters and the RPS engineering team involved with measurements. This study had an important contribution from Prof. Mark Donelan, who passed away in the beginning of March 2018. Prof. Mark Donelan was originally coauthor of the paper and participated directly in the analysis and estimation of momentum fluxes and ogives as well as through invaluable discussions on the wave boundary layer. The authors would also like to thank the two anonymous reviewers for their comments and suggestions.

\section{REFERENCES}

Anctil, F., M. A. Donelan, W. M. Drennan, and H. C. Graber, 1994: Eddy-correlation measurements of air-sea fluxes from a discus buoy.J. Atmos. Oceanic Technol., 11, 1144-1150, https://doi.org/ 10.1175/1520-0426(1994)011<1144:ECMOAS>2.0.CO;2.
Babanin, A. V., and Y. P. Soloviev, 1998: Variability of directional spectra of wind-generated waves, studied by means of wave staff arrays. Mar. Freshw. Res., 49, 89-101, https://doi.org/ 10.1071/MF96126.

_ J. McConochie, and D. Chalikov, 2018: Winds near the surface of waves: Observations and modeling. J. Phys. Oceanogr., 48, 1079-1088, https://doi.org/10.1175/JPO-D-17-0009.1.

Black, P. G., and Coauthors, 2007: Air-sea exchange in hurricanes: Synthesis of observations from the coupled boundary layer air-sea transfer experiment. Bull. Amer. Meteor. Soc., 88, 357-374, https://doi.org/10.1175/BAMS-88-3-357.

Chalikov, D., 1995: The parameterization of the wave boundary layer. J. Phys. Oceanogr., 25, 1333-1349, https://doi.org/ 10.1175/1520-0485(1995)025<1333:TPOTWB > 2.0.CO;2.

_ wind and waves and the theory of the wave boundary layer. Bound.-Layer Meteor., 138, 1-41, https://doi.org/10.1007/ s10546-010-9543-7.

Donelan, M. A., 1990: Air-sea interactions. Ocean Engineering Science, B. LeMehaute and D. M. Hanes, Eds., The Sea-Ideas and Observations on Progress in the Study of the Seas, Vol. 9 , John Wiley and Sons, 239-292.

_ , and W. J. Plant, 2009: A threshold for wind-wave growth. J. Geophys. Res., 114, C07012, https://doi.org/10.1029/ 2008JC005238.

- B. Haus, N. Reul, W. Plant, M. Stiassnie, H. Graber, O. Brown, and E. Saltzman, 2004: On the limiting aerodynamic roughness of the ocean in very strong winds. Geophys. Res. Lett., 31, L18306, https://doi.org/10.1029/2004GL019460.

_ A. V. Babanin, I. R. Young, and M. L. Banner, 2006: Wavefollower field measurements of the wind-input spectral function. Part II: Parameterization of the wind input. J. Phys. Oceanogr., 36, 1672-1689, https://doi.org/10.1175/JPO2933.1.

Drennan, W. M., H. C. Graber, D. Hauser, and C. Quentin, 2003: On the wave age dependence of wind stress over pure wind seas. J. Geophys. Res., 108, 8062, https://doi.org/10.1029/ 2000JC000715.

Edson, J. B., A. A. Hinton, K. E. Prada, J. E. Hare, and C. W. Fairall, 1998: Direct covariance flux estimates from mobile platforms at sea. J. Atmos. Oceanic Technol., 15, 547-562, https://doi.org/10.1175/1520-0426(1998)015<0547:DCFEFM> 2.0.CO;2.

- , and Coauthors, 2013: On the exchange of momentum over the open ocean. J. Phys. Oceanogr., 43, 1589-1610, https:// doi.org/10.1175/JPO-D-12-0173.1.

Emanuel, K. A., 1995: Sensitivity of tropical cyclones to surface exchange coefficients and a revised steady-state model incorporating eye dynamics. J. Atmos. Sci., 52, 3969-3976, https://doi.org/10.1175/1520-0469(1995)052<3969:SOTCTS > 2.0.CO;2.

García-Nava, H., F. J. Ocampo-Torres, P. Osuna, and M. A. Donelan, 2009: Wind stress in the presence of swell under moderate to strong wind conditions. J. Geophys. Res. Oceans, 114, C12008, https://doi.org/10.1029/2009JC005389.

Holthuijsen, L. H., M. D. Powell, and J. D. Pietrzak, 2012: Wind and waves in extreme hurricanes. J. Geophys. Res., 117, C09003, https://doi.org/10.1029/2012JC007983.

Jeong, D., B. Haus, and M. Donelan, 2012: Enthalpy transfer across the air-water interface in high winds including spray. J. Atmos. Sci., 69, 2733-2748, https://doi.org/10.1175/JAS-D-11-0260.1.

Komen, G. J., L. Cavaleri, M. Donelan, K. Hasselmann, S. Hasselmann, and P. Janssen, 1994: Dynamics and Modelling of Ocean Waves. Cambridge University Press, 556 pp. 
Komori, S., K. Iwano, N. Takagaki, R. Onishi, R. Kurose, K. Takahashi, and N. Suzuki, 2018: Laboratory measurements of heat transfer and drag coefficients at extremely high wind speeds. J. Phys. Oceanogr., 48, 959-974, https://doi.org/10.1175/ JPO-D-17-0243.1.

Kudryavtsev, V. N., and V. K. Makin, 2001: The impact of air-flow separation on the drag of the sea surface. Bound.-Layer Meteor., 98, 155-171, https://doi.org/10.1023/A:1018719917275.

Large, W. G., and S. Pond, 1981: Open ocean momentum flux measurements in moderate to strong winds. J. Phys. Oceanogr., 11, 324-336, https://doi.org/10.1175/1520-0485(1981)011<0324: OOMFMI>2.0.CO;2.

Liu, Q., A. Babanin, Y. Fan, S. Zieger, C. Guan, and I.-J. Moon, 2017: Numerical simulations of ocean surface waves under hurricane conditions: Assessment of existing model performance. Ocean Modell., 118, 73-93, https://doi.org/10.1016/ j.ocemod.2017.08.005.

Miyake, M., R. W. Stewart, and R. W. Burling, 1970: Spectra and cospectra of turbulence over water. Quart. J. Roy. Meteor. Soc., 96, 138-143, https://doi.org/10.1002/qj.49709640714.

Monin, A. S., and A. M. F. Obukhov, 1954: Basic laws of turbulent mixing in the surface layer of the atmosphere. Tr. Geofiz. Inst., Akad. Nauk SSSR, 24, 163-197.

Paulson, C. A., 1970: The mathematical representation of wind speed and temperature profiles in the unstable atmospheric surface layer. J. Appl. Meteor., 9, 857-861, https://doi.org/ 10.1175/1520-0450(1970)009<0857:TMROWS > 2.0.CO;2.

Peduzzi, P., B. Chatenoux, H. Dao, A. De Bono, C. Herold, J. Kossin, F. Mouton, and O. Nordbeck, 2012: Global trends in tropical cyclone risk. Nat. Climate Change, 2, 289-294, https:// doi.org/10.1038/nclimate1410.
Potter, H., H. C. Graber, N. J. Williams, C. O. Collins, R. J. Ramos, and W. M. Drennan, 2015: In situ measurements of momentum fluxes in typhoons. J. Atmos. Sci., 72, 104-118, https:// doi.org/10.1175/JAS-D-14-0025.1.

Powell, M. D., P. J. Vickery, and T. A. Reinhold, 2003: Reduced drag coefficient for high wind speeds in tropical cyclones. Nature, 422, 279-283, https://doi.org/10.1038/nature01481.

Rogers, R., and Coauthors, 2006: The intensity forecasting experiment: A NOAA multiyear field program for improving tropical cyclone intensity forecasts. Bull. Amer. Meteor. Soc., 87, 1523-1538, https://doi.org/10.1175/BAMS-87-11-1523.

Smith, S. D., 1988: Coefficients for sea surface wind stress, heat flux, and wind profiles as a function of wind speed and temperature. J. Geophys. Res., 93, 15 467-15 472, https://doi.org/10.1029/ JC093iC12p15467.

Takagaki, N., S. Komori, N. Suzuki, K. Iwano, T. Kuramoto, S. Shimada, R. Kurose, and K. Takahashi, 2012: Strong correlation between the drag coefficient and the shape of the wind sea spectrum over a broad range of wind speeds. Geophys. Res. Lett., 39, L23604, https://doi.org/10.1029/2012GL053988.

Toffoli, A., A. V. Babanin, M. A. Donelan, B. K. Haus, and D. Jeong, 2011: Estimating sea spray volume with a laser altimeter. J. Atmos. Oceanic Technol., 28, 1177-1183, https:// doi.org/10.1175/2011JTECHO827.1.

Tsagareli, K. N., A. V. Babanin, D. J. Walker, and I. R. Young, 2010: Numerical investigation of spectral evolution of wind waves. Part I: Wind-input source function. J. Phys. Oceanogr., 40, 656-666, https://doi.org/10.1175/2009JPO4345.1.

Young, I. R., 2006: Directional spectra of hurricane wind waves. J. Geophys. Res., 111, C08020, https://doi.org/10.1029/ 2006JC003540. 